\title{
PEMAKNAAN COVER MAJALAH TEMPO (Analisis Semiotika Cover Majalah Tempo Edisi 16 September-22 September 2019)
}

\author{
Noval Setiawan \\ Universitas Islam Negeri Sunan Kalijaga
}

\section{Abstract}

The study entitled "The Meaning of Tempo Magazine Cover (Tempo Magazine Cover September 16-September 22 2019, entitled Promise Staying Promise)" aims to find out the meaning from the meaning of illustrations, texts and color on the magazine cover. The method used in this research is descriptive qualitative method with Roland Barthes's semiotic analysis approach, which examines signs through three stages of analysis namely denotation, connotation, mythology. The results of this study might reveal that the magazine cover of this edition shows the properties possessed by Mr. Jokowi as seen from the depiction of the face shape in the illustrations. The meaning of denotation, both the meaning of shadow, clothing and expression is illustrated. While the connotation of the illustration is about the public's expectation of the revision of the KPK Law. As for the characteristics of President Jokowi's expression with his eyes closed and lips purely expressing something and his nose stretching out, that Mr. Jokowi is a liar. Furthermore, the mythological meaning found behind the illustration is a picture that contains assumptions about the unrelated Jokowi's promises and the President's responsibility towards the Revision of the KPK Law. Then in the headline and subheadline text and the black color in the nose's shadow, there is a provocation in it related to the ideology of the tempo magazine. The conclusion of this study, that the visual images contained in the magazine cover tempo "Promise Staying Promise" have a meaning contained therein.
\end{abstract}

\section{Keywords}

Tempo Magazine Cover, Illustration, Semiotics Roland Barthes.

Correspondence Contact Setiawannova1974@gmail.com

\section{PENDAHULUAN}

Berbicara tentang teknologi komunikasi berhubungan dengan perangkat yang akan digunakan untuk menyebarkan informasi yang diinginkan kepada khalayak secara luas, perangkat tersebut sering kita sebut sebagai media komunikasi massa. Media komunikasi massa yaitu media komunikasi modern yang sifatnya serentak yang ditunjukan kepada sejumlah khalayak melalui media cetak ataupun melalui media elektronik, sehingga suatu pesan yang sama bisa diterima secara bersama dan seketika (Rakhmat: 2003: 189).

Penyebaran informasi pada media massa mulai mengalami perkembangan dalam bentuk penyajian informasinya dan penyampaian. Banyaknya media online yang bermunculan membuat sebuah media cetak harus bekerja keras dalam bersaing untuk mendapatkan tempat kepercayaan di kalangan masyarakat, terutama untuk media cetak seperti majalah.

Majalah akan terasa kurang sempurna tanpa keberadaan gambar ilustrasi di dalamnya. Visualisasi yaitu langkah-langkah untuk membuat sesuatu yang abstrak kurang jelas menjadi lebih jelas secara visual yang bisa menarik nafsu pembaca, dan dapat membantu seseorang untuk menganalisis, merencanakan dan juga memutuskan suatu problem dengan cara berimajinasi pada kejadian yang sebenarnya (Kusmiati dkk, 1999: 36). Majalah juga bisa menjadi pelapor dalam menampilkan atau memberitakan peristiwa kejadian dengan ciri khas tersendiri dan berani dalam penulisan fakta-faktanya yaitu majalah tempo. 
Akhir-akhir ini media massa beramai-ramai memberitakan tentang revisi Undang-Undang KPK dan terpilihnya, Ketua KPK baru, Firli Bahuri yang cacat kode etik. Kritikan masyarakat dan akademisi mewarnai media massa maupun media sosial agar KPK harus diperkuat. Tak terkecuali Majalah Tempo dalam covernya yang menampilkan gambar Presiden Jokowi dan Selulet. Bahkan, sekelompok orang yang mengatasnamakan Jokowi Mania melaporkan Majalah Tempo ke Dewan Pers. Mereka mengakui keberatan terhadap cover Majalah Tempo dengan gambar Jokowi dengan bayangan hidung panjang seperti pinokio.

Majalah tempo selalu memiliki gebrakan tersendiri, seperti beberapa cover majalah tempo yang kontroversial. Salah satunya adalah majalah tempo edisi 16 September-22 September 2019. Dalam cover tergambar Presiden yang terdapat bayangan pinokio. Walaupun sudah sangat jelas foto atau gambar yang ada pada sebuah cover, oleh karena itu penulis tertarik untuk membahas atau mengkaji. Pemaknaan makna akan berbeda-beda bila seseorang ataupun sekelompok berada di luar lingkungan yang berbeda. Maka dari itu untuk menyamakan persepsi yang berbeda-beda, adanya analisis semiotika.

Untuk itu, perlunya menganalisis secara komunikasi (semiotika). Pada sebuah media, ideologi merupakan komponen utama yang terbentuk dari awal pendirian sebuah media massa. Artinya, Majalah Tempo berusaha sebagai penyambung masyarakat dan pemerintahan, berada di antaranya dengan sikap kritis. Kaitannya dengan Majalah Tempo ini, harus mengedepankan argumentasi ilimiah bagaimana sudut pandang Majalah Tempo.

Penulis akan mengkaji dengan salah satu bidang keilmuan komunikasi yaitu analisis semiotika yang mempelajari tanda-tanda, sehingga diharapkan dapat membantu siapa saja yang membaca majalah tempountuk memahami makna dan pesan yang ingin disampaikan. Dengan adanya kajian ini juga penulis berharap agar ada cover-cover terbaik dari majalah yang bisa menyampaikan pesan didalamnya dengan tampilan yang menarik, unik, edukatif dan mudah di ingat.

\section{KAJIAN TEORITIK}

\section{Komunikasi Massa}

Komunikasi massa yaitu proses guna menciptaan arti bersama media massa dan khalayak (Baran, 2012: 7). Sering dengan perkembangnya teknologi komunikasi, media komunikasi massapun semakin canggih dan kompleks, seperti media cetak (koran, majalah, tabloid, dsb).

Komunikasi ini mempunyai akibat tertentu menurut Liliweri (2004:39), secara umum ada tiga akibat komunikasi massa diantara: (a) efek kognitif, yaitu dimana pesan isi komunikasi massa dapat menyebabkan khalayak berubah dalam hal pengetahuan, sudut pandang, dan pendapat terhadap sesuatu yang didapatkan. (b) efek afektif, yaitu dimana isi pesan komunikasi massa bisa menyebabkan berubahnya perasaan tertentu dari khalayak. (c) efek konatif, dimana isi pesan komunikasi massa menyebabkan seseorang mengambil keputusan untuk melakukan sesuatu atau tidak melakukan apapun.

\section{Komunikasi Visual}

Desain komunikasi visual yaitu suatu semiotika khusus, dengan menggunakan tanda dan ciri yang khas, yang membedakan dengan sistem semiotika seni. Contohnya, sampul majalah harus dibuat semenarik mungkin agar calon pembaca tertarik untuk membeli majalah tersebut, karena biasanya sebelum membeli calon pembaca melihat dahulu sampulnya. Strategi semacam ini sengaja dilakukan karena produk desain komunikasi visual, yang salah satunya adalah sampul majalah hanyalah sekedar alat pembius bagi produsen untuk berburu konsumen. 


\section{Sampul Majalah}

Sampul majalah adalah sampul halaman depan yang membuat identitas perusahaan dan menghimpun isi pemberitaan verbal dan visual yang berkaitan dengan materi pemberitaan agar menarik pembaca. Unsur-unsur yang harus ada pada sebuah sampul majalah adalah ukuran dasar dari majalah tersebut (ukuran saku atau ukuran tabloid), logo, fotografi warna dasar, keterangan mengenai jadwal penerbitan, headline (judul artikel dan sub judul artikel) (Efendy, 1999: 79).

Sampul dalam sebuah majalah merupakan bagian yang tidak dapat dipisahkan. Peran sampul sangat penting, karena pada saat akan membeli majalah yang dilihat pertama kali adalah sampul atau gambar ilustrasinya. Pemilihan judul (teks) harus singkat, mudah dibaca, mudah dimengerti dan secara langsung dapat menginformasikan isi yang terkandung didalamnya. Jika tampilan sampul dibuat menarik maka akan membuat pembaca tertarik untuk membeli majalah tersebut. (Trisna, 2015).

\section{Semiotika Roland Barthes}

Di dalam ilmu semiotika, metode Roland Barthes dikenal sebagai metode yang mengkritisi metode semiotika Saussure. Metode semiotika Barthes dikenal sebagai semiotika bertingkat yang menganilisis lebih mendalam dengan mengkaitkan mitos salah satu area penting yang dirambah Barthes dalam studinya tentang tanda adalah peran pembaca. Sistem Barthes ini tersebut dengan konotasi, yang di dalam Mythogies-nya secara tegas ia bedakan dari dentasi atas sistem pemaknaan tataran pertama (Sobur, 2009: 68-69). Dibawah ini peta tanda Roland Barthes.

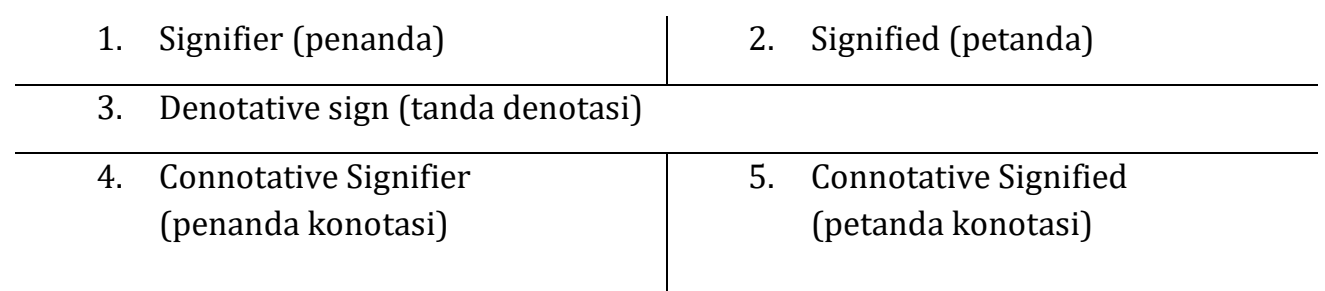

6. Connotative sign (tanda konotasi)

Setidaknya ada tiga unsur utama dalam analisis semiotika yang dikembangkan Barthes yaitu:

a. Denotatif

Seperti yang dijelaskan Lyons (dalam Sobur, 2009: 263) bahwa denotasi memagang peranan penting di dalam pengujaran, yakni memaknai suatu objek secara nyata dalam hal ini yakni diartikan sebagai makna harafiah, makna yang sesungguhnya (Tutur Rupa vol.1. Hanz Kristian Agung, 2019: 5).

b. Konotatif

Metode konotatif sendiri yakni gabungan dari beberapa gambaran/ pengujaran saat melihat suatu hal (denotatif) saat bersinggungan dengan petanda (Tutur Rupa vol.1. Hanz Kristian Agung, 2019: 5).

c. Mitos

Mitos memiliki fungsi sebagai pembenaraan dari nilai-nilai dominan pada suatu tempat yang berlaku pada masa tertentu. 


\section{METODE PENELITIAN}

Metode jurnal ini yang digunakan dalam penelitian adalah metode analisis semiotika yang bersifat kualitatif deskriptif yang bertujuan membuat deskriptif secara sistematis, faktual, dan akurat tentang fakta-fakta dan sifat-sifat populasi atau objek-objek tertentu (Kriyantono, 2006: 69). Konsep analisis Roland Barthes membagi tiga signifikasi, pertama makna denotatif ialah makna yang sesungguhnya atau makna harfiah. Kedua makna konotasi ialah makna yang tidak eksplisit. Ketiga makna mitologi, mitos adalah cerita yang digunakan suatu kebudayaan untuk menjelaskan atau memahami dari beberapa realitas atau alam.

Dalam masalah ini subjek peneliti adalah cover majalah tempo edisi 16 September- 22 September 2019, dan teks yang terdapat pada cover sebagai keterangan dari foto yang ditampilkan. Sesuai dengan apa yang menjadi topiknya, maka objek penelitian ini adalah meneliti petanda, objek, dan interpretasi peneliti mengenai gambar Presiden Jokowi pada cover majalah tempo edisi tersebut.

\section{HASIL DAN PEMBAHASAN}

Pada hal ini disajikan hasil analisis dan interpretasi data yang dilakukan pada poster Jokowi di majalah tempo edisi 16 september - 22 September 2019. Dimana peneliti akan memaparkan data, dengan menggunakan metode denotasi, konotasi, serta mitos sesuai dengan teori Roland Bartesh. Dalam poster tempo terdapat bayangan hidung pinokio. Pada poster tempo memiliki berbagai elemen-elemen desain visual seperti "tipografi, Text, Visual, Warna serta objek". Berikut gambar dari cover majalah Tempo.

Gambar 1. Cover majalah Tempo edisi 16 September - 22 September 2019

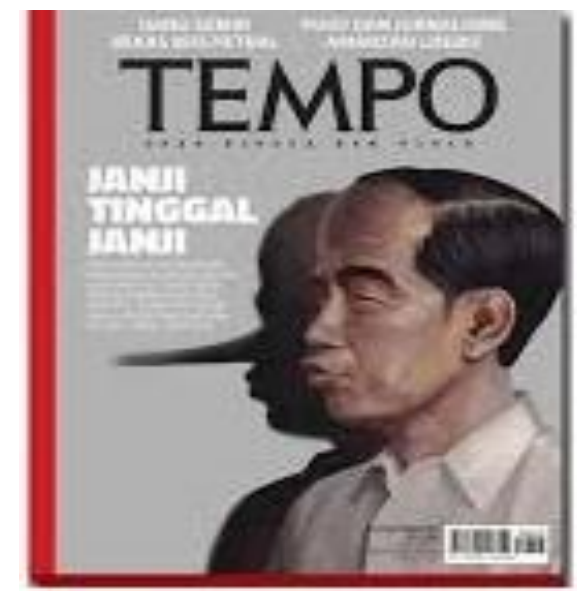

Tanda bayangan hidung berwarna hitam, memiliki maksud dan tujuan agar audience melihat poster tempo langsung tertuju pada bayangan hidung Pak Jokowi seperti pinokio serta mempertegas kepada audience bahwa poster tersebut merupakan kritik kepada pemerintah, khususnya kepada Pak Jokowi.

Pada poster tempo juga terdapat kata-kata mutiara yaitu tulisan Janji Tinggal Janji. Pada poster tempo dapat di identifikasi beberapa makna denotasi, konotasi serta serta mitos yang ada di dalam poster tersebut yang akan di jabarkan dalam table analisis semiotika milik Roland Barthes: 


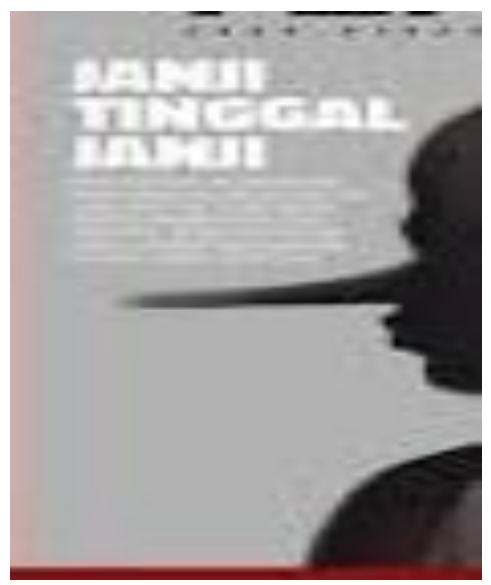

Dalam potongan gambar 1 pada majalah tempo diatas terdapat bayangan pak Jokowi yang berhidung panjang, para audience di ajak berfikir bahwa hidung panjang pada pinokio mempunyai maksud seorang pembohong yang tidak terelasi janji-janjinya, Tulisan "Janji Tinggal Janji" tampak mencolok. Dengan diikuti tulisan "para pegiat antikorupsi menuding presiden ingkar janji perihal penguatan komisi pemberantasan korupsi".

Potongan Gambar 2

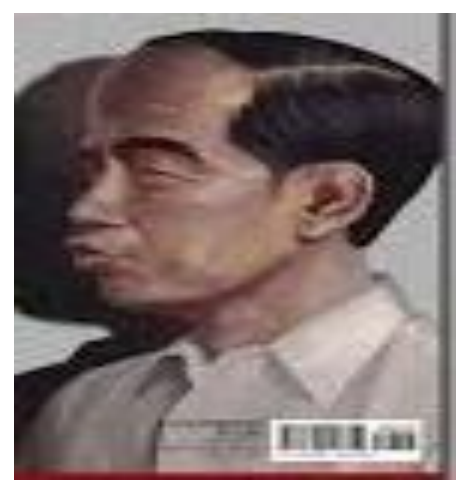

Dalam sampul majalah terdapat visual atau gambar seorang Presiden yang sedang cemberut dan memakai kemeja putih, dari gambar tersebut secara tidak langsung para audience yang melihat sampul majalah diajak berpikir bahwa tugas seorang presiden itu tidak mudah. Oleh sebab itu, seakan-akan mengiatkan kita bahwa bangsa Indonesia memiliki banyak masalah persoalan dan memiliki tanggung jawab yang besar untuk membersihkan bangsa Indonesia dari kejahatan korupsi.

\section{Makna Denotasi, Konotasi dan Mitologi}

Analisis Makna Denotasi Ilustrasi pada cover majalah Tempo Edisi 16-22 September 2019

Dilihat dari pandangan peneliti memaknai gambar ilustrasi tersebut secara denotasi memunculkan perspektif karena dalam gambar cover tersebut ada satu tokoh yang mencolok 
yaitu Pak Jokowi. Pada cover majalah tersebut terdapat bayangan hidung yang memanjang yang menunjukan karakter dari seorang Jokowi, maka makna denotasi, bisa ditafsirkan secara semiotika Roland Barthes, baik makna bayangan hidung panjang, serta teks headline dan subheadline tertulis "Janji Tinggal Janji" maupun ekspresi yang digambarkan, karena majalah tempo memiliki idiologi yang kritis sesuai dengan ekspetasi masyarakat, artinya gambaran realitas yang ada sesuai ruh demokrasi. Dengan melihat ideologi Tempo sebagai suatu media yang kritis sesuai dengan konstitusi dan ruh demokrasi. Dalam hal ini majalah tempo sedang mengkritik seorang presiden Jokowi.

\section{Analisis Makna Konotasi Ilustrasi pada cover majalah Tempo edisi 16-22 September 2019}

Sedangkan tahapan signifikasi tahap dua, yaitu hal yang mencerminkan nilai-nilai yang terdapat dari tanda atau konotasi. Adapun ciri-ciri di atas dapat diambil makna, pertama background dalam majalah Tempo "Janji Tinggal Janji" terdapat selulet warna hitam dengan hidung memanjang. Kedua dengan mimik wajah Presiden Jokowi dengan mata tertutup dan dengan bibir monyong mengekspresikan sesuatu. Dalam hal ini, Tempo pada illustrator cover majalahnya menyebutkan bahwa: "gambar tersebut merupakan metafora dari pemberitaan dalam majalah tersebut, yakni polemik Revisi UU KPK dan tanggung jawab pemerintah" hal ini berbeda dengan pandangan semiotika yang melihat makna konotasi dari gambar tersebut, menyatakan: "secara konotasi gambar cover ini, menggambarkan Pak Jokowi bukan hanya bayangan hidung yang panjang dan mimik wajah serta bibir monyong tetapi ada makna didalamnya yaitu menunjukan karakter sifat kepribadaan yang pembohong, presiden ingkar janji dalam penguatan KPK."

Oleh karena itu, dilihat dari makna konotatif terhadap gambar ilustrasi cover tersebut menanda ada makna-makna tertentu yang secara kasat mata kita tidak ketahui apa makna dibalik gambar-gambar yang ada dalam cover majalah Tempo tersebut.

\section{Analisis Makna Mitologi Ilustrasi pada cover majalah Tempo edisi 16-22 September 2019}

Setelah menganalisis makna konotasi dari gambar ilustrasi majalah Tempo edisi 16-22 September 2019 ini maka akan diperoleh signifikasi tahap ketiga yaitu makna mitologi pada ilustrasi gambar tersebut. Makna mitos dari ilustrasi gambar bayangan hidung yang memanjang artinya tidak terealisasinya janji-janji Jokowi dan dari ilustrasi mimik wajah serta bibir monyong Jokowi mengandung mitos bahwa adanya tanggung jawab Presiden terhadap revisi Undang-Undang KPK.

Apabila gambar cover majalah tempo tersebut menyatakan pemberitaan Presiden, yang bisa disebut kegiatan politik. Berbicara mengenai politik tidak lepas dari pembicaraan masyarakat dan ini bisa dikatakan sebagai komunikasi massa.

\section{KESIMPULAN}

Berdasarkan analisis dan pembahasan mengenai makna pada cover tempo edisi 16 September-22 September 2019, maka ada beberapa kesimpulan dari hasil penelitian ini:

1) Makna denotasi, ilustrasi di cover majalah tempo edisi 16-22 September 2019 digambarkan secara baik, sehingga peneliti bisa mengetahui makna denotasinya secara jelas. Dalam ilustrasi cover majalah tempo ini yang pasti kita ketahui yaitu gambar bayangan hidung yang memanjang, maupun mimik ekspresi Jokowi dengan bibir monyong, Artinya Tempo sebagai suatu media yang kritis sesuai dengan konstitusi dan ruh demokrasi.

2) Makna konotasi dalam cover majalah tempo tersebut dengan judul "Janji Tinggal Janji" terdapat makna tentang ekspetasi masyarakat atas Revisi UU KPK. 
3) Makna mitologi dalam cover majalah tempo edisi 16- 22 September 2019 yaitu tidak terelasinya janji-janji Jokowi dan adanya tanggung jawab Presiden terhadap revisi UU KPK.

Jadi, gambar visual yang terdapat dalam cover majalah Tempo edisi 16-22 September 2019 yang terdiri dari ilustrasi, teks, dan warna memiliki makna yang tergandung di dalamnya.

\section{DAFTAR PUSTAKA}

Baran. 2012. Pengantar Komunikasi Massa Melek Media dan Budaya jilid 1 edisi 5.Jakarta: Erlangga.

Budiman, Kris. 2011. Semiotika Visual : Konsep, Isu, dan Problem Ikonsitas. Yogyakarta : Jalasutra.

Cangara, Hafied. 2005. Pengantar Ilmu Komunikasi. Jakarta: Raja Grafindo.

Efendy, Onong Uchjana. 1999. Kamus Komunikasi . Bandung: Mandar Maju Komunikasi.

Hanz Kristian Agung. “ Analisis Makna Iklan Layanan Masyarakat Uber Versi Boxes-Ayo Kita Unclocked Jakarta”.Jurnal Tutur Rupa Vol.1 No.2 Februari 2019.

Iskandar, D. S. “Analisis Semiotika Roland Barthes pada Jurnalisme Online”. Jurnal Interect, Vol 4 No 2, 2015. 61-87

Kriyantono, Rachmat. 2006. Teknik Praktis Riset Komunikasi. Jakarta: Kencana.

Kusumastuti, Diyah, R. “Analisis Semiotika Pada Cover Majalah Tempo Edisi 23 Februari-1 Maret 2015”. Jurnal Ilmu Komunikasi. Vol 1 No 1 Tahun 2015, 335-368.

Kusmiati, A., Astuti, S., dan Suptandar, P. 1999. Teori Dasar Desain Komunikasi Visual. Jakarta: Djambatan.

Permana, R.S.M. “Makna Tri Tangtu Di Buana yang Mengandung Aspek Komunikasi Politik dalam Fragmen Cerita Prahyangan”Jurnal Kajian Komunikasi, Vol. 3,(23), 173-191.

Rakhmat, Jalaludin. 2003. Psikologi Komunikasi. Bandung: Rosdakarya.

Sobur, A. 2009. Semiotika Komunikasi. Bandung: PT. Remaja Rosdakarya.

Tanjung, Yohanes. “ Nilai Eksklusivitas Dalam Karya Foto Cover Majalah Tempo Edisi 4351 Tentang Kasus Bom Sariah 2016”. Jurnal Komunikasi.Vol 9, No.2, Desember 2017, Hal 112-125.

Tinarbuko,Sunbo. 2008. Semiotika Komunikasi Visual. Yogyakarta : Jalasutra

Yuniati, Ulfa. “Analisis Semiotika Karikatur Tiga Malarangeng Pada Sampul Depan Majalah Tempo Edisi 17-23 Desember 2012” Jurnal Rasi Vol 1 No.1 tahun 2019.

Yusran, Wildan. “Analisis Semiotika Atas Sampul Majalah Tempo Jakarta (Rizal Ramli Petarung atau Peraung)”. Jurnal Informasi Kajian Ilmu Komunikasi. Vol 47 Nomor 1 juni 2007. 